\section{BMJ Open Respiratory Research}

\title{
Symptom severity and its effect on health-related quality of life over time in patients with pulmonary hypertension: a multisite longitudinal cohort study
}

\author{
Janelle Yorke, ${ }^{1}$ Christi Deaton, ${ }^{2}$ Malcolm Campbell, ${ }^{1}$ Linda McGowen, ${ }^{3}$ \\ Paul Sephton, ${ }^{4}$ David G Kiely, ${ }^{4,5}$ lain Armstrong ${ }^{4}$
}

To cite: Yorke J, Deaton C, Campbell M, et al. Symptom severity and its effect on health-related quality of life over time in patients with pulmonary hypertension: a multisite longitudinal cohort study. BMJ Open Resp Res 2018;5:e000263. doi:10.1136/ bmjresp-2017-000263

Received 19 November 2017 Revised 5 February 2018

A) Check for updates

${ }^{1}$ Division of Nursing, Midwifery and Social Work, School of Health Sciences, University of Manchester, Manchester, UK

${ }^{2}$ Cambridge Institute of Public Health, University of Cambridge School of Clinical Medicine, Cambridge, UK ${ }^{3}$ School of Healthcare, University of Leeds, Leeds, UK ${ }^{4}$ Sheffield Pulmonary Vascular Disease Unit, Royal Hallamshire Hospital, Sheffield, UK

${ }^{5}$ Department of Infection, Immunity and Cardiovascular Disease, University of Sheffield, Sheffield, UK

Correspondence to Dr Janelle Yorke; janelle.yorke@manchester. ac.uk

\section{ABSTRACT}

Introduction The aim of this cohort study was to examine health-related quality of life (HRQoL) and symptomatology in patients with pulmonary hypertension $(\mathrm{PH})$ and explore factors that influence its evolution over time.

Methods A prospective longitudinal multisite cohort study. Participants were recruited from specialist UK PH centres and completed a questionnaire pack at baseline, 6, 12 and 18 months to assess HRQoL (emPHasis-10), dyspnoea, fatigue, sleep, anxiety and depression.

Results 185 patients entered the study at baseline and $126(68 \%)$ completed month 18. At baseline, patients had significant impairment of HRQoL, anxiety, depression, dyspnoea and severe fatigue. No significant changes, apart from a reduction in the Hospital Anxiety and Depression Scale-Anxiety score $(\mathrm{P}=0.04)$, were observed over 18 months. Depression and dyspnoea were predictors of HRQoL ( $P=0.002$ and $P=0.03$, respectively). Oxygen use was also associated with diminished HRQOL and increased symptom severity.

Conclusion Patients with PH experience high levels of symptom severity and the negative impact on HRQOL was unchanged over time. The use of oxygen therapy, in particular, was associated with a significant impact on $\mathrm{HRQ}$ oL. Further study of factors impacting HRQoL and interventions that target a combination of physiological and psychosocial consequences of living with $\mathrm{PH}$ are needed.

\section{INTRODUCTION}

Pulmonary hypertension $(\mathrm{PH})$ is an umbrella term used to describe a rare heterogeneous group of diseases defined at cardiac catheterisation as a mean pulmonary artery pressure of at least $25 \mathrm{~mm} \mathrm{Hg} .{ }^{1}$ It ranges from mild elevations of pulmonary artery pressure frequently seen in the context of severe cardiac and respiratory disease to severe elevations of pulmonary artery pressure seen in patients with rare forms of $\mathrm{PH}$ such as pulmonary arterial hypertension and chronic thromboembolic pulmonary hypertension. It is classified into the following five separate groups

\section{Key messages}

Although people with PH may be living for longer, they are doing so under the weight of a considerable burden of symptoms that negatively impacts health-related quality of life.

- The use of oxygen therapy, in particular, is associated with self-reported symptom severity and poorer health-related quality of life.

- Recognizing the importance of these symptoms and the need for their regular assessment may help us to offer specific interventions to patients to help improve or maintain health-related quality of life in the long term.

according to similar clinical, pathological and haemodynamic characteristics: Group 1 refers to the subtypes of pulmonary hypertension associated with abnormalities in the arterioles, the small branches of the pulmonary arteries, such as idiopathic pulmonary hypertension; Groups 2 and 3 refer to $\mathrm{PH}$ caused by left heart disease and lung disease, respectively; Group 4 refers to $\mathrm{PH}$ secondary to chronic thromboembolic PH; and Group 5 includes other less common causes that do not fit into any of the other four groups. ${ }^{1}$ In this paper, the term $\mathrm{PH}$ is used to denote Groups 1, 4 and 5.

Patients present with a range of symptoms, which are typically related to right ventricular dysfunction, and include dyspnoea, fatigue, weakness, chest pain and syncope. ${ }^{12}$ Symptoms are present on physical exertion, and as the condition progresses, symptoms often occur at rest and affect health-related quality of life (HRQoL). ${ }^{1-4}$ Psychological symptoms such as anxiety, depression and panic disorders have also been reported. ${ }^{5-12}$ 
Since there is currently no available cure, treatment is aimed at alleviating symptoms and slowing disease progression. ${ }^{1}$ Although recent advances in pharmacotherapy have led to improved survival rates and slower disease progression, ${ }^{13-15}$ the symptom burden of $\mathrm{PH}$ remains high. ${ }^{3} 816$ In addition, treatment may be associated with adverse reactions that can have a significant negative effect on HRQoL. ${ }^{16-18}$

In the past, assessment of patients with $\mathrm{PH}$ relied on functional and haemodynamic measurements. However, the importance of HRQoL is becoming increasingly recognised. ${ }^{5-7}$ 19-21 Since HRQoL is a measure of overall well-being, it is affected by both physical and mental factors, and studies in patients with $\mathrm{PH}$ indicate that both these domains of HRQoL are substantially impaired in patients with $\mathrm{PH}^{6}{ }^{6}{ }^{20} 22$ the degree of impairment becoming greater as functional class (FC) increases. ${ }^{22}{ }^{23}$ Health-related quality of life has also been shown to correlate with survival in patients with $\mathrm{PH} .{ }^{24-26}$ Qualitative and cross-sectional studies carried out to describe patients' experiences of living with $\mathrm{PH}$ have illustrated its impact on their lives and their need/ability to adapt their lifestyles to the condition over time. ${ }^{81618}$

In a survey conducted by the European Pulmonary Hypertension Association of 455 patients and carers in five countries, ${ }^{23}$ over half of patients reported that $\mathrm{PH}$ had a significant impact on daily life: for example, taking part in exercise or sport, climbing stairs and performing everyday tasks such as housework or food shopping. Work and employment were major issues, with their consequent effect on household income and personal relationships. The US Food and Drug Administration's Voice of the Patient initiative also underlined the chronic and debilitating effect of $\mathrm{PH}$ on patients' lives and the difficulties they experience in finding effective and tolerable treatments. ${ }^{17}$

Most studies that have investigated the patient's experience of living with $\mathrm{PH}$ and its effect on HRQoL have been cross-sectional, and long-term longitudinal data are currently lacking. The aim of this study was to examine various aspects of patient-reported HRQoL over an 18-month period in patients living with $\mathrm{PH}$ and to explore which factors predict a decline in HRQoL over time.

\section{METHODS}

\section{Participants}

Patients aged 18years or more who had a medically confirmed diagnosis of $\mathrm{PH}$ and were being treated at a UK specialist centre were eligible for enrolment in this prospective longitudinal cohort study. Those with chronic thromboembolic disease suitable for surgery (or who had received successful surgery), terminal disease and/or severe and enduring mental illness were excluded from the study.

As multilevel regression was used for quantitative analysis, and several models were fitted, sample size was calculated using rule of thumb for regression. ${ }^{27} \mathrm{~A}$ sample size of 194 was considered sufficient to fit a model with up to 18 independent variables, assuming medium-sized relationships between the dependent variable and the independent variables, $5 \%$ significance and $80 \%$ power. The recruitment target was 240 participants to allow for a minimum of $15 \%$ attrition throughout the study.

Participants were recruited between July 2013 and January 2014, from across all UK specialist PH centres $(\mathrm{n}=8)$ and via the Pulmonary Hypertension Association (PHA) UK research database, and followed for 18 months. They were approached during their routine clinic visit or via an invitation letter sent to their home with a reply envelope addressed to PHA UK so that they could obtain further information about the study if they wished. Questionnaire packs were sent to the participant's home for self-completion and return within 1 week. Appropriate ethical approval was granted (Ref: 13/NW/0345) and written informed consent was obtained prior to study entry.

\section{Data collection}

Demographic and clinical data, including age, gender, diagnosis, time since diagnosis, medications, comorbidities, oxygen use and $6 \mathrm{~min}$ walk/shuttle test, were extracted from the participant's notes at recruitment, and at 6,12 and 18 months, if available (patients with $\mathrm{PH}$ generally visit their specialist centre for review at 6-month intervals). Participants also completed the questionnaires outlined in table 1 at the same 6-month intervals to explore a range of HRQoL and symptom-related variables.

\section{Data analysis}

Data were analysed using Stata V.13.1. Statistical significance was set at $<0.05$. Clinical and demographic data analyses were descriptive. Questionnaire scores were calculated according to corresponding scoring algorithms, and multilevel regression methods were used to examine the changes in the various scores between the four time points. Two-level models were used with individual measurements nested within participants. The $\chi^{2}$ test, unpaired t-test and Mann-Whitney $\mathrm{U}$ test were used to compare differences in factors between dropouts and non-dropouts. Subsequently, multiple logistic regression analysis was performed to examine the joint association with dropout, using backwards selection to retain important variables only.

Multilevel linear regression was used to explore factors associated with HRQoL, and associations between each predictor variable and emPHasis-10 using data from all time points. First, a series of analyses was performed for each factor, with and without adjustments for diagnosis, age and gender. Subsequently, the associations between predictor variables and emPHasis-10 score were examined, also adjusted for diagnosis, age and gender, using backwards selection to retain statistically significant factors only. Multilevel regression methods were also 
Table 1 Tests and questionnaires analysed in the study

emPHasis-10 This PH-specific HRQoL questionnaire consists of 10 items, each on a scale of 0-5. Scores range from 0 to 50 , higher scores indicating poorer health status. For the purposes of this study, the key assessment is a change in score over time that may indicate that an individual's condition has improved (lower score) or deteriorated (higher score) ${ }^{38}$

Dyspnoea-12 Each item in this 12-item questionnaire scores from 0 (never) to 3 (severe). It examines specific aspects of dyspnoea, with an emphasis on how people physically perceive the sensation and its emotional consequences. It uses simple summation scoring to provide scores from 0 to 36 , higher scores corresponding to greater shortness of breath. The questionnaire has been validated for use in a number of cardiopulmonary conditions ${ }^{39}$

Fatigue Severity Scale

This nine-item questionnaire was developed to evaluate disabling fatigue. Each item is rated on a sevenpoint Likert scale, which ranges from strongly disagree to strongly agree. All nine items are combined into a total score, higher total scores indicating a more pronounced effect of fatigue on everyday life ${ }^{40}$

Medical Outcomes The Sleep Problems Index used in this study consists of nine items that originate from the MOS-Sleep Study Sleep Index Scale. It assesses initiation (time to fall asleep), quantity (hours of sleep each night), maintenance,

(MOS-Sleep Index) perceived adequacy, respiratory problems and somnolence. Scores are converted into 1-100, higher scores being indicative of worse sleep ${ }^{29}$

Hospital Anxiety and A widely used tool that assesses psychological distress (seven items measure anxiety, the score ranging Depression Scale from 0 to 21; and seven items measure depression, the score ranging from 0 to 21); higher scores indicate greater emotional distress, and scores $>8$ suggest the presence of clinically relevant anxiety/ depression $^{41}$

HRQoL, health-related quality of life; $\mathrm{PH}$, pulmonary hypertension.

used to compare oxygen use for measurements from all time points combined for participants not using oxygen 'at all' with a combined group using oxygen 'night-time only' / 'as I need it' / 'all of the time'.

\section{RESULTS}

\section{Participant demographics}

Questionnaires were sent to 262 patients. Of these, 185 were returned at baseline ( $70 \%$ response), 153 at 6 months, 140 at 12 months and 126 at 18 months, giving a rate of attrition of $32 \%$ by the end of the study.

Patient demographics are shown in table 2. Mean patient age was 56 years, $68 \%$ were women, most had Group 1 PH (133, 73\%; of whom 66, 36\% were idiopathic pulmonary arterial hypertension $(\mathrm{PAH}))$ and $39 \%$ were on PH monotherapy, and $51 \%$ on combination therapy with $13 \%$ on parenteral prostanoid. There were no statistically significant differences in any of the patient-reported measures at baseline and follow-up between the different $\mathrm{PH}$ diagnostic groups.

Few participants lived alone $(16 \%)$ or were in full-time employment $(9 \%)$. The majority reported WHO FC II $(34 \%)$ or III $(42 \%)$ at baseline.

There were missing data for the walk test results at each time point: baseline missing data for 32/185 (17\%) of patients; 6 months missing data for $77 / 153(50 \%)$ of patients still in the study at this time point; 12 months missing data for 68/140 (49\%) of patients still in the study at this time point; and 18 months missing data for $60 / 126$ $(48 \%)$ of patients still in the study at this time point. This prevented meaningful analyses to be conducted to test correlations between decline/improvement in walk tests and HRQoL or symptom experience over time.

\section{Changes in test and questionnaire scores over time}

Multilevel regression was used to assess the changes in test and questionnaire scores over time, and these are shown in table 3. Scores for fatigue were more than double the normative scores at baseline and were higher than reported cut-off values for chronic fatigue syndrome. ${ }^{28}$ No significant changes in test or questionnaire scores were observed over 18 months, apart from a significant reduction in the HADS-Anxiety score $(\mathrm{P}=0.04)$, indicating a slight decrease in emotional distress from baseline (table 3 ).

\section{Factors associated with attrition}

A total of 59 participants (32\%) dropped out of the study between baseline and 18 months (deaths $\mathrm{n}=11$ and received a transplant $n=4)$. These patients had significantly higher WHO FC ( $\mathrm{P}=0.02$; table 4$)$, and HADS-Depression and Dyspnoea-12 scores $(\mathrm{P}=0.002$ and $\mathrm{P}=0.03$, respectively; table 4 ). When the joint association between these factors and dropout was examined, only the HADS-Depression score was significantly associated with dropout, higher scores being associated with a greater risk of dropout (OR 1.14; $95 \%$ CI 1.05 to 1.24). Following adjustment for HADS-Depression score, neither WHO FC nor Dyspnoea-12 score had any additional effect on study discontinuation.

\section{Factors associated with emPHasis-10 score}

When analysed separately, scores for Dyspnoea-12, FSS, MOS-Sleep Index, HADS-Anxiety, HADS-Depression and patient-reported WHO FC were significantly associated with HRQoL (emPHasis-10; all $\mathrm{P}<0.001$ ), higher 


\begin{tabular}{|c|c|}
\hline Demographic & $\begin{array}{l}\text { Patients }(n=185) \\
n(\%)\end{array}$ \\
\hline Mean age, years (SD) & $56.0(13.1)$ \\
\hline Mean 6 min walk test, metres (SD) & $365(146)^{*}$ \\
\hline $\begin{array}{l}\text { Mean incremental shuttle walk test, } \\
\text { metres (SD) }\end{array}$ & $298(198)^{\star}$ \\
\hline \multicolumn{2}{|l|}{ Gender } \\
\hline Male & 59 (32) \\
\hline Female & $126(68)$ \\
\hline \multicolumn{2}{|l|}{$\mathrm{PH}$ diagnosis } \\
\hline Idiopathic PAH & $66(36)$ \\
\hline CTEPH & $20(11)$ \\
\hline CTD PAH & $32(18)$ \\
\hline Congenital PAH & $35(19)$ \\
\hline Familial PH & $2(1)$ \\
\hline Other & $6(3)$ \\
\hline Unsure & $21(12)$ \\
\hline \multicolumn{2}{|l|}{ Lives with } \\
\hline Family & $140(76)$ \\
\hline Alone & $30(16)$ \\
\hline Friends & $3(2)$ \\
\hline Other & $11(6)$ \\
\hline \multicolumn{2}{|l|}{ Employment } \\
\hline Full time & $17(9)$ \\
\hline Part time & $26(14)$ \\
\hline Not employed & $61(34)$ \\
\hline Retired & $77(43)$ \\
\hline \multicolumn{2}{|l|}{ WHO FC (patient reported) } \\
\hline Class I & $8(5)$ \\
\hline Class II & $60(34)$ \\
\hline Class III & $75(42)$ \\
\hline Class IV & $34(19)$ \\
\hline \multicolumn{2}{|l|}{ HADS-Anxiety score } \\
\hline $0-7$ & $360(61)$ \\
\hline $8-10$ & $108(18)$ \\
\hline $11-14$ & $89(15)$ \\
\hline $15-21$ & $32(5)$ \\
\hline \multicolumn{2}{|l|}{ HADS-Depression score } \\
\hline $0-7$ & $426(73)$ \\
\hline $8-10$ & $103(18)$ \\
\hline $11-14$ & $47(8)$ \\
\hline $15-21$ & $11(2)$ \\
\hline \multicolumn{2}{|l|}{ Oxygen } \\
\hline Not at all & $111(61)$ \\
\hline Night-time only & $19(10)$ \\
\hline As I need it & 25 (14) \\
\hline
\end{tabular}

Continued

\begin{tabular}{lc}
\hline Table 2 Continued & $\begin{array}{l}\text { Patients }(\mathbf{n}=\mathbf{1 8 5}) \\
\mathbf{n}(\%)\end{array}$ \\
$\begin{array}{l}\text { Demographic } \\
\text { All of the time }\end{array}$ & $27(15)$ \\
Therapy & $70(39)$ \\
Single & $92(51)$ \\
Dual & $11(6)$ \\
Triple & $7(4)$ \\
No treatment & $165(93)$ \\
Nebuliser therapy & $13(7)$ \\
No & $173(97)$ \\
Yes & $5(3)$ \\
Subcutaneous therapy & \\
No & $173(97)$ \\
Yes & $5(3)$ \\
Intravenous therapy & \\
No & \\
Yes &
\end{tabular}

*Baseline values for the 6 min walk test and incremental shuttle walk test were missing in 31 and 10 patients, respectively. CTD, connective tissue disease; CTEPH, chronic thromboembolic pulmonary hypertension; HADS, Hospital Anxiety and Depression Scale; $\mathrm{PAH}$, pulmonary arterial hypertension; $\mathrm{PH}$, pulmonary hypertension; WHO FC, WHO functional class.

scores reflecting poorer HRQoL (table 5). Significance was attained both with and without adjustment for diagnosis, age and gender. When included in the same model, Dyspnoea-12, FSS, HADS-Anxiety, HADS-Depression and WHO FC were predictors of HRQoL, each significantly associated with emPHasis-10 score $(\mathrm{P}<0.001$; table 6). After adjustment for other variables, the relationship between the MOS-Sleep Index and emPHasis-10 was statistically non-significant. The association between HADS-Depression score and emPHasis-10 score was linear after adjustment, with a unit increase in the former corresponding to an average 0.5 unit increase in the latter.

\section{Comparisons of scores with and without oxygen}

Thirty-nine participants (21\%) were receiving oxygen at the start of the study, six of whom used oxygen continuously. Multilevel regression demonstrated that those using oxygen had significantly higher emPHasis-10, FSS, HADS-Anxiety, HADS-Depression and Dyspnoea-12 scores (table 7). The need for oxygen had no significant effect on participants' sleep pattern (MOS-Sleep Index).

\section{DISCUSSION}

To our knowledge, this is the first longitudinal, prospective, large cohort study to assess important symptom-based variables in $\mathrm{PH}$ and to examine how they affect HRQoL in real-life clinical practice. We have shown that although patients may be living for longer, they are doing so 


\begin{tabular}{lcllll}
\hline \multicolumn{7}{l}{ Table 3} & Changes in questionnaire scores over time & & & \\
\hline Score & Baseline $(\mathbf{n}=\mathbf{1 8 5})$ & $\mathbf{6}$ months $\mathbf{( n = 1 5 3 )}$ & $\mathbf{1 2 \text { months }} \mathbf{( n = 1 4 0 )}$ & $\mathbf{1 8 m o n t h s ~ ( n = 1 2 6 )}$ & P value \\
\hline emPHasis-10 & $27.0(12.0)$ & $25.8(11.6)$ & $25.4(11.8)$ & $25.4(12.3)$ & 0.54 \\
Dyspnoea-12 & $11.5(9.4)$ & $10.5(9.2)$ & $10.3(8.8)$ & $10.8(9.2)$ & 0.20 \\
FSS & $5.1(1.6)$ & $4.8(1.6)$ & $4.8(1.6)$ & $4.7(1.7)$ & 0.07 \\
MOS-Sleep Index & $39.4(19.2)$ & $38.8(20.0)$ & $37.7(19.0)$ & $39.4(19.7)$ & 0.48 \\
HADS-Anxiety & $7.1(4.7)$ & $6.3(4.4)$ & $6.3(4.3)$ & $6.6(4.5)$ & 0.04 \\
HADS-Depression & $6.0(3.8)$ & $5.4(3.8)$ & $5.2(3.5)$ & $5.3(3.6)$ & 0.39
\end{tabular}

Multilevel regression methods were used to examine changes in the various scores among the four time points. Figures reported are the mean (SD) score at each time point.

FSS, Fatigue Severity Scale; HADS, Hospital Anxiety and Depression Scale; MOS, Medical Outcomes Study.

under the weight of a considerable burden of symptoms. Despite improvements in survival of patients with $\mathrm{PH}$, this study has illustrated that symptom severity is high, and although there were improvements in anxiety, the negative impact on HRQoL was unchanged over time. This highlights the need for further study of factors influencing, and additional interventions to manage, the impact of this chronic condition on HRQoL.

The association between HRQoL, as measured by emPHasis-10, and breathlessness, fatigue, depression, anxiety and sleep was assessed over time, and a strong relationship was demonstrated between each of these factors and HRQoL, particularly between HRQoL and breathlessness and depression. These findings are in line with those reported by Matura $e t a l,{ }^{21}$ who conducted a cross-sectional study to look at interference of symptoms with HRQoL in patients with $\mathrm{PH}$ and found that breathlessness on exertion, fatigue and difficulty in sleeping had the greatest effect on daily life in these patients.

Dyspnoea, fatigue, anxiety, depression, WHO FC and poor sleep were all found to be predictors of reduced HRQoL, as assessed by emPHasis-10. Following regression analysis, the relationship between poor sleep and HRQoL was no longer significant. Sleep quality in the sample was poor overall, with a mean MOS-Sleep score greater than 35 points ${ }^{29}$ at all time points. Many of the factors affecting HRQoL, such as physical and psychological symptoms, may have also affected quality of sleep in these patients.

\begin{tabular}{llcl}
\hline Table 4 Factors associated with dropout & & & \\
\hline Variable & No dropout (n=126) & Dropout (n=59) & P value \\
\hline Mean age, years (SD) & $55.5(13.7)$ & $57.0(11.6)$ & 0.47 \\
Gender, $\mathrm{n}(\%)$ & & & 0.08 \\
\hline Male & $35(28)$ & $24(41)$ & \\
\hline Female & $91(72)$ & $35(59)$ & 0.69 \\
\hline PH diagnosis, $\mathrm{n}(\%)$ & & & \\
\hline Idiopathic PH & $49(39)$ & $17(30)$ & \\
\hline CTEPH & $14(11)$ & $6(11)$ & \\
\hline CTD & $19(15)$ & $13(23)$ & \\
\hline Congenital PH & $24(19)$ & $11(20)$ & 0.03 \\
\hline Other & $20(16)$ & $12(16)$ & 0.14 \\
\hline Median Dyspnoea-12 score (IQR) & $9(2-16)$ & $14(5-19)$ & 0.16 \\
\hline Median FSS score (IQR) & $5.2(3.8-6.2)$ & $5.6(4.6-6.6)$ & 0.002 \\
\hline Mean HADS-Anxiety score (SD) & $6.8(4.5)$ & $7.9(5.0)$ & 0.08 \\
\hline Mean HADS-Depression score (SD) & $5.4(3.6)$ & $7.3(4.1)$ & 0.02 \\
\hline Mean MOS-Sleep Index score (SD) & $37.7(19.1)$ & $43.2(19.0)$ & \\
\hline WHO FC, $n$ (\%) & & & $15(27)$ \\
\hline Class I/II & $53(43)$ & $23(42)$ & $17(31)$ \\
\hline Class III & $52(43)$ & $17(14)$ & \\
\hline Class IV & & & \\
\hline
\end{tabular}

CTD, connective tissue disease; CTEPH, chronic thromboembolic pulmonary hypertension; FSS, Fatigue Severity Scale; HADS, Hospital Anxiety and Depression Scale; MOS, Medical Outcomes Study; PH, pulmonary hypertension; WHO FC, WHO functional class. 
Table 5 Association between individual predictor factors and emPHasis-10 scores ( $\mathrm{n}=126)$

\begin{tabular}{|c|c|c|c|c|c|}
\hline \multirow[b]{2}{*}{ Variable } & \multirow[b]{2}{*}{ Category/term } & \multicolumn{2}{|l|}{ Unadjusted } & \multicolumn{2}{|l|}{ Adjusted* } \\
\hline & & Coefficient $(95 \% \mathrm{Cl})$ & $P$ value & Coefficient $(95 \% \mathrm{Cl})$ & $P$ value \\
\hline \multirow[t]{2}{*}{ Dyspnoea-12† } & Linear term & 6.5 (5.4 to 7.6$)$ & $<0.001$ & 6.7 (5.6 to 7.9$)$ & $<0.001$ \\
\hline & Squared term & $-0.4(-0.6$ to 0.2$)$ & & $-0.4(-0.6$ to 0.2$)$ & \\
\hline MOS-Sleep Index $\ddagger$ & - & 1.7 (1.2 to 2.2$)$ & $<0.001$ & 1.7 (1.2 to 2.2$)$ & $<0.001$ \\
\hline FSS† & - & 3.2 (2.8 to 3.7$)$ & $<0.001$ & 3.3 (2.8 to 3.7 ) & $<0.001$ \\
\hline HADS-Anxiety & - & 1.1 (0.9 to 1.3$)$ & $<0.001$ & 1.1 (0.9 to 1.3$)$ & $<0.001$ \\
\hline \multirow[t]{2}{*}{ HADS-Depression } & Linear term & 2.2 (1.6 to 2.7$)$ & $<0.001$ & 2.2 (1.7 to 2.8$)$ & $<0.001$ \\
\hline & Squared term & $-0.06(-0.09$ to 0.02$)$ & & $-0.06(-0.09$ to 0.02$)$ & \\
\hline \multirow[t]{3}{*}{ WHO FC (patient reported) } & $\mathrm{FC} \mathrm{I/II}$ & 0 & $<0.001$ & 0 & $<0.001$ \\
\hline & FC III & 5.1 (3.7 to 6.6$)$ & & 5.3 (3.8 to 6.7 ) & \\
\hline & FC IV & 7.5 (5.4 to 9.5$)$ & & 7.5 (5.4 to 9.6$)$ & \\
\hline
\end{tabular}

*Adjusted for diagnosis, age and gender.

†Regression coefficients reported for a 5-unit increase in predictor variable.

†Regression coefficients reported for a 10-unit increase in predictor variable.

FSS, Fatigue Severity Scale; HADS, Hospital Anxiety and Depression Scale; MOS, Medical Outcomes Study; WHO FC, WHO functional class.

Talwar $e$ t $a \rho^{30}$ carried out a retrospective study in 36 patients with $\mathrm{PH}$ to examine the relationships between dyspnoea, depression and HRQoL using the generic SF-36 scale (36-item Short Form Health Survey) and found a non-linear, negative relationship between the physical and mental components of this scale, perceived dyspnoea increasing with the severity of depression. However, in contrast to our findings, they observed that the SF-36 mental component did not worsen until a certain severity of dyspnoea and depression was reached. An earlier study that used several scales to measure dyspnoea and depression in patients with chronic respiratory disease observed that depression was a significant predictor $(\mathrm{P}<0.05)$ of self-rated dyspnoea. ${ }^{31}$

Further research including patients with severe disease is needed, particularly as those with worse WHO FC, and high dyspnoea or depression scores were more likely to drop out of the study. Depression is a key variable as it continued to be associated with patient dropout after other factors, including dyspnoea, had been excluded. Depression was also clearly associated with the emPHasis-10 score. The non-significant decline in most study variables, apart from anxiety, may have reached significance if those with worse WHO FC and depression were retained in the study.

Oxygen use was associated with significant impairment in HRQoL and a significant increase in all symptoms assessed in the study $(\mathrm{P} \leq 0.001)$, apart from sleep. Previous studies have also found oxygen use to be associated with reduced HRQoL. Although patients with $\mathrm{PH}$ may adapt to oxygen therapy over time, ${ }^{32}$ it is cumbersome to use and places restrictions on patients' daily lives that can lead to reduced HRQoL. Previous investigations into patients' experiences of living with $\mathrm{PH}$ reported that having to use oxygen therapy was more distressing to them than other aspects of treatment, including use of intravenous medications. ${ }^{18}$

Table 6 Association between combined predictor factors and emPHasis-10 scores ( $n=126)$

\begin{tabular}{llcc}
\hline Variable & Category/term & Coefficient $(\mathbf{9 5 \%} \mathbf{C l})^{*}$ & P value \\
\hline Dyspnoea-12† & Linear term & $4.5(3.4$ to 5.6$)$ & $<0.001$ \\
\hline FSS $\dagger$ & Squared term & $-0.4(-0.6$ to -0.2$)$ & \\
\hline HADS-Anxiety & - & $1.7(1.3$ to 2.2$)$ & $<0.001$ \\
HADS-Depression & - & $0.3(0.1$ to 0.5$)$ & 0.001 \\
WHO FC (patient reported) & - & $0.5(0.3$ to 0.8$)$ & $<0.001$ \\
& FC I/II & 0 & $<0.001$ \\
& FC III & $2.5(1.2$ to 3.8$)$ & \\
\hline
\end{tabular}

${ }^{*}$ Adjusted for diagnosis, age and gender.

†Regression coefficients reported for a 5-unit increase in predictor variable.

FSS, Fatigue Severity Scale; HADS, Hospital Anxiety and Depression Scale; WHO FC, WHO functional class. 


\begin{tabular}{|c|c|c|c|c|}
\hline Variable* & No oxygen $(n=111)$ & Oxygen $(n=x \times 71)$ & Difference $(95 \% \mathrm{Cl})$ & P valuef \\
\hline Mean emPHasis-10 score (SD)‡ & $22.5(12.0)$ & $32.5(8.4)$ & $7.4(5.0$ to 9.9$)$ & $<0.001$ \\
\hline Mean FSS score (SD)‡ & $4.5(1.7)$ & $5.5(1.4)$ & 0.8 (0.5 to 1.2$)$ & $<0.001$ \\
\hline Mean MOS-Sleep Index (SD)‡ & $37.2(19.6)$ & $42.2(18.6)$ & $3.1(-1.2$ to 7.4$)$ & 0.16 \\
\hline Mean HADS-Anxiety score (SD) $\ddagger$ & $5.8(4.4)$ & $8.0(4.3)$ & $1.6(0.7$ to 2.6$)$ & 0.001 \\
\hline Mean HADS-Depression score (SD) $\ddagger$ & $4.6(3.4)$ & $7.1(3.7)$ & 1.7 (0.9 to 2.5$)$ & $<0.001$ \\
\hline Median Dyspnoea-12 score (IQR)§ & $6(1-14)$ & $15(9-22)$ & 1.93 (1.55 to 2.42$)$ & $<0.001$ \\
\hline
\end{tabular}

*Mean values for total scores across all time points combined.

$\dagger P$ values indicate significance of the overall difference between the four time points.

‡For variables found to be approximately normally distributed, mean and SD were summarised: mean difference using oxygen versus no oxygen.

§For the variable found to be non-normally distributed, the median and IQR preferred was summarised, and the ratio of scores in participants using oxygen versus no oxygen is reported on a log scale.

FSS, Fatigue Severity Scale; HADS, Hospital Anxiety and Depression Scale; MOS, Medical Outcomes Study.

Studies in patients with chronic obstructive pulmonary disease (COPD) or interstitial lung disease (ILD) have reported similar findings. A study that compared oxygen-dependent patients with COPD with matched control patients with COPD found that all domains of HRQoL (SF-36 score) were profoundly impaired in oxygen-dependent patients compared with the control group. ${ }^{33}$ In qualitative studies, patients with COPD stated their dislike of carrying and maintaining oxygen equipment, many relying on their carer to carry the equipment when they ventured outside. They were embarrassed about using oxygen in public, distressed at losing their independence and worried that their oxygen would run out if they left the house. ${ }^{34}{ }^{35}$ Similar concerns were expressed by patients with ILD, who highlighted the practical challenges of oxygen therapy, loss of independence, social stigma and restrictions on their lifestyles. ${ }^{36} 37$ This highlights the need for further study with respect to the efficacy and impact of oxygen therapy in patients with $\mathrm{PH}$ and cautions against its indiscriminate use.

Our study is based on participants completing questionnaires sent to their home for self-completion and return within 1 week. This approach has weaknesses with a significant number of missing data over time. Furthermore, it was not possible to always link self-completed outcomes with objective measures such as walk distance tests, extracted from patient records-these were often weeks apart with significant levels of missing data. A limitation of this study is that although patients from all WHO FCs were recruited to the study, $76 \%$ of participants were in FC II or III (patient reported) on enrolment and over $90 \%$ were receiving oral therapy, and therefore few data were available for patients in stage IV PH. In addition, participants with a higher FC were more likely to drop out of the study, further reducing the amount of study information on patients who were no longer receiving oral therapy and who may have specific HRQoL issues. Finally, longer follow-up including the collection of patient self-report outcomes and objective clinical measures concurrently is needed to assess how HRQoL and symptom severity evolves as time goes on.

This study has highlighted a number of key factors, including dyspnoea, depression, anxiety, fatigue and quality of sleep that may predict a decline in HRQoL over time in patients with $\mathrm{PH}$. Recognising the importance of these symptoms and the need for their regular assessment may help us to offer specific interventions to patients, as appropriate, to help improve or maintain HRQoL in the long term.

Acknowledgements We are grateful to Cath Billings for comments on early manuscript drafts. Editorial assistance was provided by Solaris Health.

Contributors JY and IA conceived the original study idea. JY, IA, CD, LMcG, MC, PS and DGK all contributed to the study design, data analysis and interpretation. PS collected data. All authors contributed to the preparation of the manuscript.

Funding Funding received by the Pulmonary Hypertension Association UK. Competing interests None declared.

Patient consent Obtained.

Ethics approval North West-Lancaster 13/NW/0245.

Provenance and peer review Not commissioned; externally peer reviewed.

Open Access This is an Open Access article distributed in accordance with the Creative Commons Attribution Non Commercial (CC BY-NC 4.0) license, which permits others to distribute, remix, adapt, build upon this work non-commercially, and license their derivative works on different terms, provided the original work is properly cited and the use is non-commercial. See: http://creativecommons.org/ licenses/by-nc/4.0/

(C) Article author(s) (or their employer(s) unless otherwise stated in the text of the article) 2018. All rights reserved. No commercial use is permitted unless otherwise expressly granted.

\section{REFERENCES}

1. Galiè N, Humbert M, Vachiery J-L, et al. 2015 ESC/ERS Guidelines for the diagnosis and treatment of pulmonary hypertension. Eur Respir J 2015;46:903-75.

2. Armstrong I, Rochnia N, Harries $\mathrm{C}$, et al. The trajectory to diagnosis with pulmonary arterial hypertension: a qualitative study. BMJ Open 2012;2:e000806.

3. Delcroix M, Howard L. Pulmonary arterial hypertension: the burden of disease and impact on quality of life. Eur Respir Rev 2015;24:621-9.

4. Cenedese E, Speich R, Dorschner L, et al. Measurement of quality of life in pulmonary hypertension and its significance. Eur Respir $J$ 2006;28:808-15. 
5. Löwe B, Gräfe K, Ufer C, et al. Anxiety and depression in patients with pulmonary hypertension. Psychosom Med 2004;66:831-6.

6. Shafazand S, Goldstein MK, Doyle RL, et al. Health-related quality of life in patients with pulmonary arterial hypertension. Chest 2004;126:1452-9.

7. Taichman DB, Shin J, Hud L, et al. Health-related quality of life in patients with pulmonary arterial hypertension. Respir Res 2005;6:92.

8. McDonough A, Matura LA, Carroll DL. Symptom experience of pulmonary arterial hypertension patients. Clin Nurs Res 2011;20:120-34.

9. White J, Hopkins RO, Glissmeyer EW, et al. Cognitive, emotional, and quality of life outcomes in patients with pulmonary arterial hypertension. Respir Res 2006;7:55.

10. McCollister DH, Beutz M, McLaughlin V, et al. Depressive symptoms in pulmonary arterial hypertension: prevalence and association with functional status. Psychosomatics 2010;51:339-339.e8.

11. Verma S, Cardenas-Garcia J, Mohapatra PR, et al. Depression in pulmonary arterial hypertension and interstitial lung diseases. N Am J Med Sci 2014;6:240-9.

12. Looper KJ, Pierre A, Dunkley DM, et al. Depressive symptoms in relation to physical functioning in pulmonary hypertension. $J$ Psychosom Res 2009;66:221-5.

13. Galiè N, Barberà JA, Frost $\mathrm{AE}$, et al. Initial use of ambrisentan plus tadalafil in pulmonary arterial hypertension. N Engl J Med 2015;373:834-44.

14. Pulido T, Adzerikho I, Channick RN, et al. Macitentan and morbidity and mortality in pulmonary arterial hypertension. $N$ Engl $\mathrm{J} \mathrm{Med}$ 2013;369:809-18.

15. Sitbon O, Channick R, Chin KM, et al. Selexipag for the treatment of pulmonary arterial hypertension. N Engl J Med 2015;373:2522-33.

16. Yorke J, Armstrong I, Bundock S. Impact of living with pulmonary hypertension: a qualitative exploration. Nurs Health $\mathrm{Sci}$ 2014:16:454-60.

17. U.S. Food and Drug Administration (FDA). The voice of the patient. A series of reports from the U.S. Food and Drug Administration's (FDA's) patient-focused development initiative. Pulmonary arterial hypertension. Last updated Dec 2014. https://www.fda. gov/downloads/forindustry/userfees/prescriptiondruguserfee/u cm429382.pdf (accessed 25 Jul 2017).

18. Flattery MP, Pinson JM, Savage L, et al. Living with pulmonary artery hypertension: patients' experiences. Heart Lung 2005;34:99-107.

19. Matura LA, McDonough A, Carroll DL. Predictors of healthrelated quality of life in patients with idiopathic pulmonary arterial hypertension. J Hosp Palliat Nurs 2012;14:283-92.

20. Matura LA, McDonough A, Carroll DL. Health-related quality of life and psychological states in patients with pulmonary arterial hypertension. J Cardiovasc Nurs 2014;29:178-84.

21. Matura LA, McDonough A, Carroll DL. Symptom interference severity and health-related quality of life in pulmonary arterial hypertension. J Pain Symptom Manage 2016;51:25-32.

22. Kukkonen M, Puhakka A, Halme M. Quality of life among pulmonary hypertension patients in Finland. Eur Clin Respir J 2016;3:26405

23. European Pulmonary Hypertension Association (PHA). The impact of pulmonary arterial hypertension (PAH) on the lives of patients and carers: results from an international survey. last updated Sep 2012. http://www.phaeurope.org/wp-content/uploads/InternationalPAH-patient-and-Carer-Survey-Report-FINAL1.pdf (accessed $25 \mathrm{Jul}$ 2017).
24. Mathai SC, Suber T, Khair RM, et al. Health-related quality of life and survival in pulmonary arterial hypertension. Ann Am Thorac Soc 2016;13:31-9.

25. Blok IM, van Riel AC, Schuuring MJ, et al. Decrease in quality of life predicts mortality in adult patients with pulmonary arterial hypertension due to congenital heart disease. Neth Heart $J$ 2015;23:278-84.

26. Rubenfire M, Lippo G, Bodini BD, et al. Evaluating health-related quality of life, work ability, and disability in pulmonary arterial hypertension: an unmet need. Chest 2009;136:597-603.

27. Tabachnik BG, Fidell LS. Using multivariate statistics. 4th Edn. Needham Heights MA: Allyn and Bacon, 2001.

28. Jason LA, Evans M, Brown M, et al. Fatigue scales and chronic fatigue syndrome: issues of sensitivity and specificity. Disabil Stud $Q$ 2011;31.

29. Stewart AL, Hays RD, Ware JE. The MOS short-form general health survey. Reliability and validity in a patient population. Med Care 1988;26:724-32.

30. Talwar A, Sahni S, Kim EJ, et al. Dyspnea, depression and health related quality of life in pulmonary arterial hypertension patients. $J$ Exerc Rehabil 2015;11:259-65.

31. Kellner R, Samet J, Pathak D. Dyspnea, anxiety, and depression in chronic respiratory impairment. Gen Hosp Psychiatry 1992;14:20-8

32. Cullen DL, Stiffler D. Long-term oxygen therapy: review from the patients' perspective. Chron Respir Dis 2009;6:141-7.

33. Lacasse $\mathrm{Y}$, Bernard $\mathrm{S}$, Martin $\mathrm{S}$, et al. Utility scores in patients with oxygen-dependent COPD: a case-control study. COPD 2015;12:510-5.

34. Arnold E, Bruton A, Donovan-Hall M, et al. Ambulatory oxygen: why do COPD patients not use their portable systems as prescribed? A qualitative study. BMC Pulm Med 2011;11:9.

35. Goldbart J, Yohannes AM, Woolrych R, et al. 'It is not going to change his life but it has picked him up': a qualitative study of perspectives on long term oxygen therapy for people with chronic obstructive pulmonary disease. Health Qual Life Outcomes 2013;11:124.

36. Khor YH, Goh NSL, McDonald CF, et al. Oxygen therapy for interstitial lung disease. A mismatch between patient expectations and experiences. Ann Am Thorac Soc 2017;14:888-95.

37. U.S. Food and Drug Administration (FDA). The voice of the patient. A series of reports from the U.S. Food and Drug Administration's (FDA's) patient-focused drug development initiative. Idiopathic pulmonary fibrosis. last updated Mar 2015. https://www.fda. gov/downloads/forindustry/userfees/prescriptiondruguserfee/u cm440829.pdf (accessed 25 Jul 2017).

38. Yorke J, Corris P, Gaine S, et al. emPHasis-10: development of a health-related quality of life measure in pulmonary hypertension. Eur Respir J 2014:43:1106-13.

39. Yorke J, Moosavi SH, Shuldham C, et al. Quantification of dyspnoea using descriptors: development and initial testing of the Dyspnoea-12. Thorax 2010;65:21-6.

40. Krupp LB, LaRocca NG, Muir-Nash J, et al. The fatigue severity scale. Application to patients with multiple sclerosis and systemic lupus erythematosus. Arch Neurol 1989;46:1121-3.

41. Zigmond AS, Snaith RP. The hospital anxiety and depression scale. Acta Psychiatr Scand 1983;67:361-70. 